\title{
Hemşirelik Öğrencilerinin Akıllı Telefon Kullanım Özelliklerinin Belirlenmesi
}

\section{The Determination of the Usage Characteristic of Smartphones in Nursing Students}

\author{
Remziye SEMERCİ ${ }^{\mathrm{a}}$ Melahat AKGÜN KOSTAK ${ }^{\mathrm{b}}$
}

\begin{abstract}
ÖZ Giriş: Bu çalışmada, hemşirelik öğrencilerinin akıllı telefon kullanım özelliklerinin belirlenmesi amaçlanmıştır. Gereç ve Yöntem: Tanımlayıcı tipte olan araştırma; Mayıs 2015 tarihinde, Trakya Üniversitesi, Sağlık Bilimleri Fakültesi Hemşirelik bölümünde öğrenim gören 298 hemşirelik öğrencisi ile yürütüldü. Araştırma verileri; araştırmacılar tarafindan geliştirilen "Anket Formu" ile toplandı. Araştırmanın verileri sayı, yüzde, ki-kare ve korelasyon analizi ile değerlendirildi. Bulgular: Öğrencilerin yaşları $20.6 \pm 1.6$ ve \%91.9'u kız ve \%93.6'sının akıllı telefonu vardı. Öğrencilerin günlük interneti kullanma süresi $318.98 \pm 233.08$ dakika idi. Öğrencilerin \%68.5'i teorik derste, \%65.4'ü klinik uygulamalarda akıllı telefonlarını kullanmakta idi. Öğrenciler akıllı telefonlarını bir saatlik teorik derste $17.84 \pm 33.30$ dakika, 8 saatlik klinik uygulama sırasında ise $52.48 \pm 65.46$ dakika kullanmakta idi. Öğrencilerin \%56'sı akıllı telefon kullanımının bireysel ilişkileri zayıflattığını ifade etti. Öğrencilerin sınıfları ile teorik derslerde ve klinik uygulamalarda akıllı telefon kullanım amaçları arasında fark bulundu $(\mathrm{p}<0.05)$. Öğrencilerin yaşları ile günlük internete bağlanma süreleri arasında negatif yönde korelasyon, klinik uygulamalarda akıllı telefon kullanım süreleri arasında pozitif yönde korelasyon vardı $(\mathrm{p}<0.05)$. Sonuç: Bu çalışmada akıllı telefon kullanımının hemşirelik öğrencileri arasında yaygın olduğu, öğrencilerin eğitimlerinde akıllı telefonlardan yararlandıkları ancak ders saatleri içerisinde ders dışı amaçlarla kullandıkları, bu durumun ders performans ve başarılarını olumsuz etkilediği saptandı.

\section{Anahtar Kelimeler:}

ABSTRACT Objective: This study was conducted to determine the usage features of smartphones in nursing students. Material and Methods: This descriptive study was conducted with 298 students at Trakya University, Faculty of Health Sciences, Department of Nursing, in May 2015. Data were collected by "Survey Form" which developed by the researchers. Data was analyzed frenquency, percentage, chi-square and correlation analysis. Results: The age of students was $20.6 \pm 1.6,91.9 \%$ of the students are girls, $93.6 \%$ of students had smartphone. Students use internet $318.98 \pm 233.08$ minutes in a day and $68.5 \%$ of students were using their smartphones during theoretical courses, $65.4 \%$ of students were using during clinical practices. Students were using smartphones $17.84 \pm$ 33.30 minutes during one-hour lectures and $52.48 \pm 65.46$ minutes during the eight-hour clinical practice. In addition, $56.0 \%$ of students stated that smartphone using decrease personal relations. There was a difference between the classes of students and the usage aim of smartphones in theoretical courses and in clinical practice $(\mathrm{p}<0.05)$. It was found a negative correlation between age of students and daily internet usage time ( $\mathrm{p}<0.05)$. It was found a positive correlation between age of students and smartphone usage time during clinical practices. Conclusion: In this study was showed smartphone using common among nursing students, students benefit from smartphones for education but students use smartphones for curricular purposes during the courses and this case negatively affects their performance and success.

\section{Giriş}

Ak1llı telefonlar, yeni medya ortamlarının sunduğu birçok özelliğe sahip olması ve en önemlisi taşına- bilir özelliği ile günlük hayatımızın vazgeçilmezleri arasında yerini almıştır $(1,2)$. Dünyanın en

Geliș Tarihi/Received: 17-01-2018/ Kabul Tarihi/Accepted: 20-07-2018

${ }^{a} A r s ̧$. Gör. Trakya Üniversitesi, Sağlık Bilimleri Fakültesi, Hemşirelik Bölümü, Edirne, e-posta: remziyesemerci@ gmail.com, ORCID: 0000-0003-1999-9179

bDoç. Dr. Trakya Üniversitesi, Sağlık Bilimleri Fakültesi, Hemşirelik Bölümü, Edirne, e-posta: akgunmel@ yahoo.com, ORCID: 0000-0003-0507-9638

Sorumlu Yazar/Correspondence: Doç. Dr. Melahat AKGÜN KOSTAK, Trakya Üniversitesi, Sağlik Bilimleri Fakültesi, Hemşirelik Bölümü, email: akgunmel@yahoo.com,

Atıf: Semerci R. Akgün Kostak M, Hemşirelik öğrencilerinin akıllı telefon kullanım özelliklerinin belirlenmesi. Sağlık Bilimleri ve Meslekleri Dergisi 2019;6(1):8-16

Citation: Semerci R. Akgün Kostak M, The determination of the usage characteristic of smartphones in nursing students. Journal of Health Science and Profession 2019;6(1):8-16 
büyük muhasebe, denetim, vergi ve yönetim danışmanlığ 1 hizmeti sunan uluslararası firmalarından biri olan "Deloitte" tarafindan yayınlanan 'State of The Global Mobile Consumer: Connectivity is core 2012' isimli mobil cihazlara ilişkin raporun sonuçlarına göre; Türkiye aralarında Amerika, Fransa, İngiltere, Kanada gibi gelişmiş Batı ülkelerinin de bulunduğu 15 ülke arasinda cep telefonundan internet kullanım sıralamasında birinci sırada yer almıştır (3). Gelişmiş ülkelerde internete bağlanmak için akıllı telefon kullanım oranı \%79 iken, gelişmekte olan ülkeler siralamasında Türkiye \%91 kullanım oranıyla ilk sırada yer almaktadır (4). Türkiye İstatistik Kurumu Nisan 2015 verilerine göre; Türkiye'deki hanelerin \%96.8'inde cep telefonu veya ak1llı telefon bulunduğu rapor edilmiştir (5).

Ak1llı telefonlar her zaman bağlantıda olmaya olanak sağladığ kullanımına da yeni bir boyut getirmektedir (1). Araştırmalarda hemşireler ve diğer sağlık çalışanlarının sosyal paylaşım ağlarına yoğun ilgi gösterdikleri bildirilmiştir (6). Akıllı telefonların yaşamımızdaki artan bu önemi, her geçen gün birçok araştırmaya konu olmakta ve bu konuda yapılan araştırmaların sayısı da her geçen gün artmaktadır $(7,8)$. İngiltere'de Von Muhlen ve Ohno-Machado'nun (2012) hekim, hemşire, diş hekimi, eczacılar ve tıp öğrencilerini kapsayan metaanaliz çalışması, sağlık çalışanlarının sosyal paylaşım ağlarını yaygın olarak kullandıklarını doğrulamaktadır (9). Kung ve Oh (2014), hemşirelerin \%93.4'ünün sosyal medyayı aktif olarak kullandığını, \%37.9'unun sosyal medya platformlarına üye olduğunu, \%31.8'inin bir blog takip ettiğini, \%19'unun twitter kullandığını ve hemşirelerin çoğunluğunun günlük 1-4 saat internette zaman geçirdiğini rapor etmişlerdir (10).

Hemşireler akıllı telefonu/interneti sağlıkla ilgili gelişmelerden haberdar olmak, sağllk personeli, aile ve hastalarıyla iletişim kurmak amacıyla da kullanmaktadırlar (11). Pitt ve Bennett (2008) hemşirelerin akıllı telefonlarını kişisel ağlar oluşturma, aile ve arkadaşlarını kontrol etme, müzik ve video indirme, spor sonuçlarını kontrol etme, sosyal imleri takip etme gibi meslekleri ile ilgili olmayan faaliyetler için daha fazla kullandıklarını rapor etmişlerdir (12).

Ak1llı telefonlar sağlı profesyonelleri için internete erişim sağlayarak onlara ilaç bilgisi, tıbbi uygulamalar, hasta eğitimleri konusunda rehberlik sağlamaktadır (13). Ancak yapılan araştırmalar bilişsel işlerde akıllı telefonun dikkati dağıtarak, konsantrasyonun azalmasına, iş performansının düşmesine ve yapılan iş süresinin uzamasına neden olduğunu göstermektedir $(14,15)$. Özellikle sağlık profesyonellerinin akıllı telefonları fazla kullanmaları hasta bakımını olumsuz etkileyerek beraberinde güvenlik risklerini de getirmektedir. Ardıç Çobaner ve Işık (2014) bu riskleri; içeriğin denetlenememesi, hastanın mahremiyetinin ve kişisel gizliliğinin ihlali, profesyonel olmayan davranışlar ve örgütsel riskler olmak üzere dört kategoriye ayırmıştır (16). Bu riskleri en aza indirmek için elektronik ve sosyal medyayı kullanan sağlık kuruluşlarının, üniversite çalışanlarının ve öğrencilerin medya kullanımını kontrol eden politikaları takip etmeleri gerekmektedir (17). Fidancioğlu, Beydağ, Gök Özer ve Kızılkaya (2009) hemşirelik ve sağlı memurluğu öğrencilerinin \%53'ünün interneti kullandıklarını belirtmişlerdir (18). Kheokao, Siriwanji, Yingrengreung ve Krirkgulthorn (2015) da Tayland'da hemşirelik öğrencilerinin sosyal medyayı yaygın olarak kullandıklarını belirtmişlerdir (17). Öğrencilerin interneti ve sosyal medyayı yaygın olarak kullanmaları ve bu durumu akıllı telefonlar aracılığıly derslerde devam ettirmeleri, öğrenciler için düşük verimlilik düzeyine ve zamanın boşa geçirilmesine neden olmaktadır (19). Ayrıca gelecekte sağlık personeli olacak öğrencilerin riskli akıllı telefon kullanım davranışlarına da zemin hazırlamaktadır (20).

Bu çalışmanın amacı geleceğin hemşirelerini oluşturacak olan hemşirelik öğrencilerinin akıllı telefon kullanım özellikleri belirlemektir. Araştırmada "Hemşirelik öğrencilerinin teorik derste akıllı telefon kullanım amaçları nelerdir?", "Hemşirelik öğrencilerinin klinik uygulamada akıllı telefon kullanım amaçları nelerdir?", "Hemşirelik öğrencilerinin akıllı telefon kullanımını etkileyen faktörler nelerdir?" sorularına yanıt aranmıştır.

\section{Gereç ve Yöntem}

Araştırmanın Tipi: Bu araştırma, tanımlayıcı tipte bir çalışmadır.

Araştırmanın Yeri: $\mathrm{Bu}$ araştırma Mayıs 2015 tarihinde Trakya Üniversitesi Sağlık Bilimleri Fakültesi, Hemşirelik Bölümü öğrencileriyle yürütüldü. 
Araştırmanın Evren ve Örneklemi: Araştırmanın evrenini Trakya Üniversitesi, Sağlık Bilimleri Fakültesi, 2014-2015 Eğitim-Öğretim yılında, hemşirelik bölümünde öğrenim gören 547 öğrenci oluşturdu. Örneklem seçimi yapılmadan tam sayım yöntemi ile evrenin tamamına ulaşılması hedeflendi. Örneklemi 01.05.2015 ile 15.05.2015 tarihleri arasında derslere devam eden, araştırmaya katılmaya gönüllü ve "Anket Formu" nu eksiksiz dolduran 298 öğrenci oluşturdu. Araştırma $\% 54.48^{\prime}$ lik katılım oranıyla tamamlandı.

Verilerin Toplaması: Veriler araştırmacılar tarafindan literatür doğrultusunda hazırlanan “Anket Formu" ile toplandı (17,18,21-24). Anket formu öğrencilerin sosyo-demografik özelliklerini (yaş, cinsiyet, sınıf, aile gelir düzeyi, aile tipi, yaşadığı yer, anne-baba eğitim düzeyi) içeren 8 soru ve akı1lı telefon kullanımı ile ilgili düşünce ve davranışlarını (akıllı telefon varlığ 1 , teorikuygulama derslerinde akıllı telefon kullanım durumu, kullanım süresi ve kullanım amaçlar vb.) içeren 22 soru olmak üzere toplam 30 sorudan oluştu. Gönüllü öğrencilere "Anket Formu” ders saatleri dişında dersliklerde yüz yüze görüşme yöntemi ile uyguland. Formun doldurulmas1 yaklaşık 5-8 dakika sürdü.

Verilerin Değerlendirilmesi: Araştırmanın verileri SPSS 19.0 programinda analiz edildi. Öğrencilerin sosyodemografik özellikleri ile akıllı telefon kullanım özellikleri ve görüşleri; sayı, yüzde, ortalama ve standart sapma ile değerlendirildi. Öğrencilerin sınıfları ile teorik derslerde ve klinik uygulamalarda akıllı telefon kullanım amaçlarının karşılaştırılmasında ki-kare testi kullanıldı. Öğrencilerin yaşı ile akıllı telefon kullanım süreleri arasındaki ilişki verilerin normal dağılım göstermemesi nedeniyle Spearman korelasyon analizi ile değerlendirildi ve 0.00 $0.25=$ çok zayıf, $0.26-0.49=$ zayıf, $0.50-0.69=$ orta, $0.70-0.89=y u ̈ k s e k, \quad 0.90-1.00=$ çok yüksek ilişki, korelasyon katsayıları esas alındı (25). p<0.05 değeri istatistiksel anlamlılık sınırı olarak kabul edildi.

Araştırmanın Etik Yönü: Araştırma için Trakya Üniversitesi Tıp Fakültesi Etik Kurulu'ndan 15.07.2015 tarihli 13/10 nolu izin, Trakya Üniversitesi Sağlık Bilimleri Fakültesi Dekanlığı ve Hemşirelik Bölüm Başkanlığı'ndan yazılı izin alındı. Öğrencilere araştırmanın amacı açıklandı, elde edilen bilgilerin bilimsel amaçla kullanılacağı, formlara isim belirtmemeleri, çalışmanın kendilerine maddi ve manevi zarar verme riskinin olmadığı söylendi Araştırmaya katılmak isteyen öğrencilere araştırmanın amacı açıklandıktan sonra sözel onamları alındı.

\section{Bulgular}

Araştırmaya katılan öğrencilerin yaşı 20.6 \pm 1.6 , \%91.9'u k1z, \%26.8'i birinci sınıf, \%29.9'u ikinci sınıf idi. Öğrencilerin günlük internete bağlanma süresi $318.98 \pm 233.08$ dakika, ak1ll telefon kullanım süreleri 1 saatlik teorik derste $17.84 \pm 3.30$ dakika ve 8 saatlik klinik uygulama sirasinda $52.48 \pm 65.46$ dakika olarak bulundu. Öğrencilerin \%93.6's1 akıllı telefonunun olduğunu, \%68.5'i teorik dersler sırasında akıllı telefonu kullandığını, \%58.4'ü teorik ders sirasinda akıllı telefon kullanımının dersi dinlemelerini engellediğini ifade etti. Öğrencilerin \%65.4'ü klinik uygulamalarda akıllı telefonu kullandığını, \%40.6's1 uygulamalarda ak1llı telefon kullanımının kendilerine engel teşkil ettiğini, \%91.9'u eğitimleri, \%90.9'u meslekleri için ak1llı telefonların gerekli olduğunu belirtmiştir. Öğrencilerin \%61.4'ü akıllı telefon kullanımının okul-ders performans ve başarıyı arttırdığını, \%29.9'u okul-ders performansin1 olumsuz etkilediğini, \%56'sı bireysel ilişkileri zayıflattığını ifade etti (Tablo 1).

Öğrencilerin sınıfları ile teorik derslerde akıllı telefonlarını oyun oynama ve zaman doldurma amacıyla kullanmaları yönünden fark bulundu $(\mathrm{p}=0.010 ; \mathrm{p}=0.020)$. Ak1llı telefonlarını ikinci sınıflar en çok oyun için, dördüncü sınıflar ise zaman doldurmak amaciyla kullanmaktadır (Tablo 2). Öğrencilerin sınıfları ile teorik derslerde akıllı telefonlarını iletişim kurma, araştırma yapma ve e-posta amaciyla kullanmaları yönünden fark görülmedi (Tablo 2).

Öğrencilerin sınıfları ile klinik uygulamalarda akıllı telefon kullanım amaçları arasında anlamlı fark vardı $(\mathrm{p}<0.05)$. Klinik uygulamalar sırasında akıllı telefonlarını dördüncü sınıflar ilaç bilgisi araştırma, tıbbi kelimelerin anlamına bakma, mesleki bilgilerini güncelleme ve iletişim kurma amacıyla, üçüncü sinıflar hastalık bilgisi araştırma amacıyla, üçüncü ve ikinci sınıflar da ödev-araştırma yapma amaciyla daha fazla kullandığı saptandı (Tablo 3). 
Tablo 1. Öğrencilerin Akıllı Telefon Kullanım Özellikleri ve Görüşleri $(\mathrm{n}=298)$

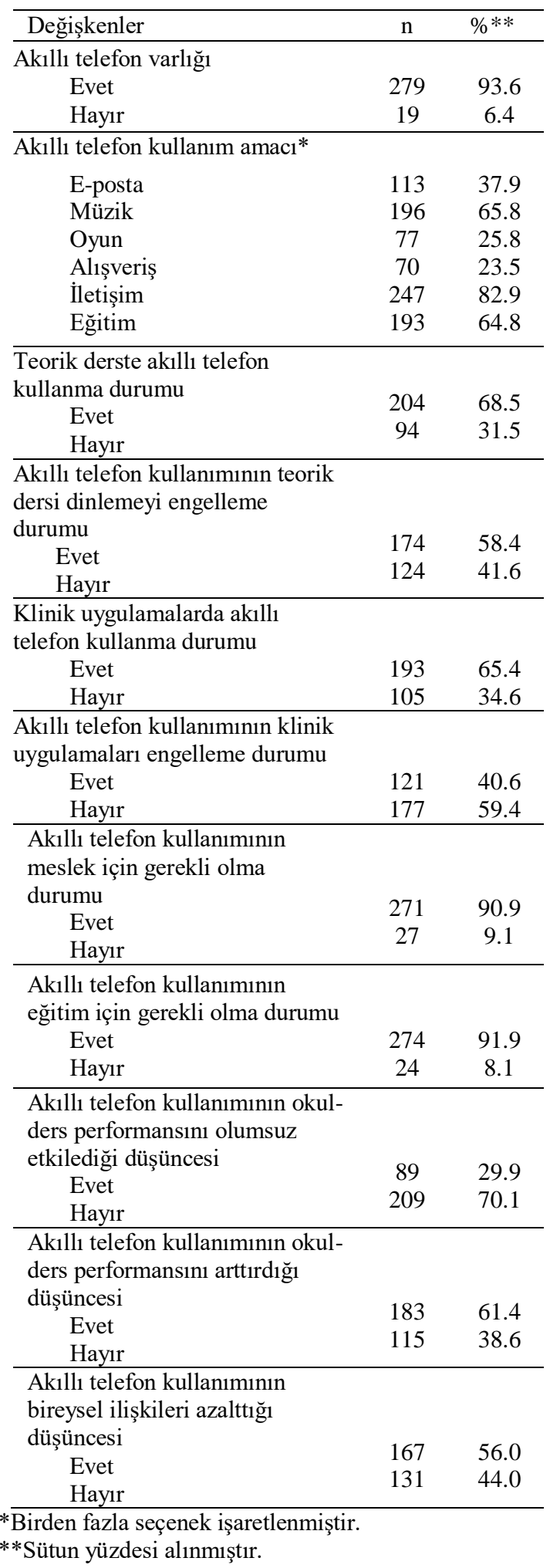

Öğrencilerin yaşları ile klinik uygulamalarda akıllı telefon kullanma süreleri arasında çok zayıf pozitif $(\mathrm{p}=0.001)$, günlük internete bağlanma süreleri ile çok zayıf negatif korelasyon vardı $(p=0.018)$. Öğrencilerin yaşları arttıkça klinik uygulamalarda akıllı telefon kullanım sürelerinin arttığı, günlük internete bağlanma sürelerinin ise azaldığ 1 belirlendi (Tablo 4).

\section{Tartışma}

Trakya Üniversitesi Sağlık Bilimleri Fakültesi Hemşirelik Bölümünde öğrenim gören 298 öğrenciyle yürütülen çalışma, hemşirelik öğrencilerinin akıllı telefonu ve interneti yaygın olarak kullandıklarını göstermektedir. $\mathrm{Bu}$ çalışmada öğrencilerin \%93.6'sının akıllı telefonu vardı ve günde ortalama 5 saat ak1llı telefonlarını kullandıkları belirlendi (Tablo 1). Literatür incelendiğinde Çakır ve Demir (2014) üniversite öğrencilerinin \% 76.2' sinin, Gümüş ve Örge (2015) meslek yüksekokulu öğrencilerinin \%98'inin, Uğur ve Turan (2015) üniversite öğrencilerinin \%97.3'ünün akıllı telefonlarını ve interneti yaygın olarak kullandıklarını saptamıştır (21,26,27). Willemse, Waller, Süss, Genner ve Huber (2012) üniversite öğrencilerinin \%79'unun, Kheokao ve arkadaşları (2015) hemşirelik öğrencilerinin \%80'inin, Sandholzer ve arkadaşları (2015) tıp öğrencilerinin \%79.9'unun akıllı telefon ve interneti kullandıklarını belirlemiştir $(17,24,28)$. $\mathrm{Bu}$ çalışmanın bulguları, literatürdeki araştırma sonuçlarına benzer şekilde, hemşirelik öğrencilerinin akıllı telefonu yaygın olarak kullandıklarını göstermektedir.

$\mathrm{Bu}$ çalışmada öğrencilerin günlük internete bağlanma süreleri $318.98 \pm 233.08$ dakika, akıllı telefon kullanım süreleri 1 saatlik teorik derste $17.84 \pm 33.30$ dakika ve 8 saatlik klinik uygulama sirasinda $52.48 \pm 65.46$ dakika olarak bulundu. Ersun ve arkadaşları (2012) hemşirelik yüksekokulu öğrencilerinin internet kullanım sürelerini günde $1.7 \pm 1.6$ saat, Gümüş ve Örgev (2015) meslek yüksekokulu öğrencilerinin \%58'inin günde en az 3-5 saat akıllı telefonlarını kullandıklarını belirtmişlerdir (22,26). Araştırma sonuçları, üniversite öğrencilerinin her geçen yıl internet ve akıllı telefon kullanımlarının arttığını görülmektedir. Bu çalışmada da öğrencilerin akıllı telefon ve interneti yaygın olarak kullandıkları saptand1. 
Tablo 2. Öğrencilerin Sınıflarına Göre Teorik Derslerde Akıllı Telefon Kullanım Amaçlarının Dağılımı (n= 298)

\begin{tabular}{|c|c|c|c|c|c|c|c|c|c|}
\hline \multirow{3}{*}{ Amaçlar } & \multicolumn{6}{|c|}{ Sinıflar } & \multirow{2}{*}{\multicolumn{2}{|c|}{ 4.Sinif }} & \multirow{3}{*}{$\chi^{2}, p$} \\
\hline & \multicolumn{2}{|c|}{ 1. Sinif } & \multicolumn{2}{|c|}{ 2. Sinif } & \multicolumn{2}{|c|}{ 3. Sinif } & & & \\
\hline & $\mathrm{n}$ & $\% *$ & $\mathrm{n}$ & $\%$ & $\mathrm{n}$ & $\%$ & $\mathrm{n}$ & $\%$ & \\
\hline \multicolumn{10}{|l|}{ Oyun oynama } \\
\hline Evet & 19 & 23.8 & 32 & 36.0 & 9 & 12.9 & 17 & 28.8 & 11.36 \\
\hline Hayır & 61 & 76.2 & 57 & 64.0 & 61 & 87.1 & 42 & 71.2 & 0.010 \\
\hline \multicolumn{10}{|l|}{ Zaman doldurma } \\
\hline Evet & 10 & 12.5 & 23 & 25.8 & 14 & 20.0 & 20 & 33.9 & 9.81 \\
\hline Hayır & 70 & 87.5 & 66 & 74.2 & 56 & 80.0 & 39 & 66.1 & 0.020 \\
\hline \multicolumn{10}{|l|}{ İletişim kurma } \\
\hline Evet & 35 & 43.8 & 47 & 52.8 & 31 & 44.3 & 35 & 59.3 & 4.48 \\
\hline Hayır & 45 & 56.2 & 42 & 47.2 & 39 & 55.7 & 24 & 40.7 & 0.214 \\
\hline \multicolumn{10}{|c|}{ Ödev-Araştırma yapma } \\
\hline Evet & 29 & 36.3 & 29 & 32.6 & 18 & 25.7 & 25 & 42.4 & 4.25 \\
\hline Hayır & 51 & 63.7 & 60 & 67.4 & 52 & 74.3 & 34 & 57.6 & 0.236 \\
\hline \multicolumn{10}{|l|}{ E-posta } \\
\hline Evet & 8 & 10.0 & 9 & 10.1 & 7 & 10.0 & 9 & 15.3 & 1.30 \\
\hline Hayır & 72 & 90.0 & 80 & 89.9 & 63 & 90.0 & 50 & 84.7 & 0.728 \\
\hline
\end{tabular}

Tablo 3. Öğrencilerin Sınıflarına Göre Klinik Uygulamalarda Akıllı Telefon Kullanım Amaçlarının Dağılımı (n = 298)

\begin{tabular}{|c|c|c|c|c|c|c|c|c|c|}
\hline \multirow{3}{*}{ Amaçlar } & \multicolumn{8}{|c|}{ Sinıflar } & \multirow{3}{*}{$\chi^{2}, p$} \\
\hline & \multicolumn{2}{|c|}{ 1. Sinif } & \multicolumn{2}{|c|}{ 2. Sinıf } & \multicolumn{2}{|c|}{ 3. Sinif } & \multicolumn{2}{|c|}{ 4. Sinif } & \\
\hline & $\mathrm{n}$ & $\% *$ & $\mathrm{n}$ & $\%$ & $\mathrm{n}$ & $\%$ & $\mathrm{n}$ & $\%$ & \\
\hline \multicolumn{10}{|c|}{ İlaç bilgisi araştırma } \\
\hline Evet & 26 & 32.5 & 52 & 58.4 & 44 & 62.9 & 41 & 69.5 & 23.499 \\
\hline Hayır & 54 & 67.5 & 37 & 41.6 & 26 & 37.1 & 18 & 30.5 & $<0.001$ \\
\hline \multicolumn{10}{|c|}{ Hastalık bilgisi araştırma } \\
\hline Evet & 19 & 23.8 & 50 & 56.2 & 43 & 61.4 & 32 & 54.2 & 27.185 \\
\hline Hayır & 61 & 76.2 & 39 & 43.8 & 27 & 38.6 & 27 & 45.8 & $<0.001$ \\
\hline \multicolumn{10}{|c|}{ T1bbi kelimelerin anlamını öğrenme } \\
\hline Evet & 26 & 32.5 & 47 & 52.8 & 36 & 51.4 & 37 & 62.7 & 13.836 \\
\hline Hayır & 54 & 67.5 & 42 & 47.2 & 24 & 48.6 & 22 & 37.3 & 0.003 \\
\hline \multicolumn{10}{|c|}{ Mesleki bilgileri güncelleme } \\
\hline Evet & 5 & 6.3 & 9 & 10.1 & 3 & 4.3 & 13 & 22.0 & 13.204 \\
\hline Hayır & 75 & 93.8 & 80 & 89.9 & 67 & 95.7 & 46 & 78.0 & 0.004 \\
\hline \multicolumn{10}{|c|}{ Ödev-Araştırma yapma } \\
\hline Evet & 17 & 21.3 & 43 & 48.3 & 35 & 50.0 & 20 & 33.9 & 18.095 \\
\hline Hayır & 63 & 78.8 & 46 & 51.7 & 35 & 50.0 & 39 & 66.1 & $<0.001$ \\
\hline \multicolumn{10}{|c|}{ İletişim Kurma } \\
\hline Evet & 15 & 18.8 & 31 & 34.8 & 21 & 30.0 & 32 & 54.2 & 19.729 \\
\hline Hayır & 65 & 81.2 & 58 & 65.2 & 49 & 70.0 & 27 & 45.8 & $<0.001$ \\
\hline
\end{tabular}

*Sütun yüzdesi alınmıştır.

Tablo 4. Öğrencilerin Yaş ile Akıllı Telefon Kullanım Süreleri Arasındaki Korelasyon Katsayıları ve Anlamlılık Düzeyi $(\mathrm{n}=298)$

\begin{tabular}{lcc}
\hline Değişkenler & \multicolumn{2}{c}{ Yaş } \\
& $\mathrm{r}_{\mathrm{s}}$ & $\mathrm{p}$ \\
\hline $\begin{array}{l}\text { Günlük internete bağlanma } \\
\text { süresi (dk.) }\end{array}$ & -0.137 & 0.018 \\
\hline $\begin{array}{l}\text { Teorik derste akıllı telefon } \\
\text { kullanım süresi (dk.) }\end{array}$ & -0.007 & 0.906 \\
\hline $\begin{array}{l}\text { Klinik uygulamalarda akıllı } \\
\text { telefon kullanım süresi } \\
\text { (dk.) }\end{array}$ & 0.217 & 0.001 \\
\hline $\begin{array}{l}\mathrm{r}_{\mathrm{s}}=\text { sperman korelasyon analizi } \\
\end{array}$ &
\end{tabular}

$\mathrm{Bu}$ çalışmada öğrencilerin çoğu teorik ders ve klinik uygulama sirasinda akillı telefon kullandıklarını ve yaklaşık yarısı teorik derste akıllı telefon kullanımının öğrenmelerine engel teşkil ettiğini belirtti (Tablo 2). Gümüş ve Örgev (2015) üniversite öğrencilerinin \%95'inin ders ortamında veya ders çalışırken telefonu yanında ya da elinin altında bulundurmak istediklerini, ayrı kalmayı ya da kapalı tutmayı düşünmediklerini, öğrencilerin \%75'inin derslerde ve 
sınavlarda telefonlarını yanlarında ya da çantalarında getirdiklerini, hatta sessize alıp açık tuttukların1, öğrencilerin \%65'i telefonla meşguliyetin dikkatlerini dağıttığını ve derslere adapte olamadıkları gibi ders çalışma sırasında zihinlerini meşgul ettiğini belirtmişlerdir (26). Cho (2014) hemşirelik öğrencilerinin \%48.5'inin akıllı telefon kullanımının ders çalışmalarını engellediğini saptamıştır (29). Cho ve Lee (2016) hemşirelik öğrencilerinin \%28'inin klinik uygulamalarda akıllı telefon kullandıklarında dikkatlerinin dağıldığını, \%27'sinin ise başkasının akıllı telefon kullanımı ile dikkatlerinin dağıldığını belirtmiştir (13). Teknolojinin yaygınlaşması ile öğrencilerin yaşamlarına giren akıllı telefonun gün geçtikçe onları kendine bağlayan bir araç konumuna geldiği, öğrencilerin hem teorik derslerde hem klinik uygulamalarda akıllı telefonlarını yaygın olarak kullandıkları görülmektedir. Ancak bu durum öğrencilerin eğitimlerini aksatma ve kişisel ilişkilerini zayıflatma riskleri açısından ele alınmasının gerekliliğini göstermektedir.

Çalışmada öğrencilerin akıllı telefonlarını daha çok iletişim kurmak amacıyla kullandikları bulundu (Tablo 3). Ersun ve arkadaşları (2012) ise hemşirelik öğrencilerinin interneti en çok araştırma yapma, Fidancıoğlu ve arkadaşları (2009) sağlık yüksekokulu öğrencilerinin eğitim için, Kheokao ve arkadaşları (2015) hemşirelik öğrencilerinin araştırma/ödev yapma için, Korkmaz ve arkadaşları (2014) hemşirelerin iletişim kurma için, Tüysüz, Balaman ve Atalar (2012) eğitim fakültesi öğrencilerinin iletişim kurma amacıyla kullandıklarını saptamışlardır $(17,18,22,30)$. Bu çalışmanın sonuçları diğer çalışma sonuçlarına benzer şekilde, üniversite öğrencilerinin akıllı telefon/interneti daha çok iletişim kurmak için kullandıklarını göstermektedir. Literatürde, akıllı telefonların taşınabilir özellikte olması ve çoklu fonksiyona (ses kaydı, video kayd1, görüntülü iletişim) sahip olmasından dolayı daha çok iletişim kurma amacıyla kullanıldığ akıllı telefonu sosyal medyadaki arkadaşları ile iletişime geçmek amaciyla bir araç olarak kullanmaktadırlar. Akıllı telefon kullanımının yararları yanında fazla kullanılmasının sosyal ilişkileri zayıflattığ 1 , konsantrasyon dağınıkl1ğna, fiziksel rahatsızlıklara; belde ve bilekte ağrıya, boyunda sertliğe, bulanık görmeye ve uyku problemlerine yol açtığı çalışmalarda belirtilmiştir (32-34). $\mathrm{Bu}$ nedenle akıllı telefonların akılcı kullanımı için; akıllı telefon kullanımının yararları yanında zararları ile ilgili çocuk ve ailelerin bilgilendirilmesi ve çocuklara erken yaşlarda akıllı telefon kullanımına yönelik kuralların uygulanması gerekmektedir. Çalışmadaki öğrencilerin yaklaşık yarısı akıllı telefon kullanımının klinik uygulamalara engel teşkil ettiğinin ve akıllı telefon kullanımının bireysel ilişkileri zayıflattığını ifade etmiştir (Tablo 1). Korkmaz ve arkadaşları (2014) da hemşirelerin sosyal ağ kullanımlarının iş verimliliği ve performansını olumsuz yönde etkilediğini bildirmişlerdir (23). Öğrencilerin akıllı telefonu kullanırken harcadıkları zamanı kontrol edemedikleri gibi kişiler arası ilişkileri de zayıflattığı yapılan araştırmalarda görülmektedir (35). Diğer taraftan öğrencilerin akıllı telefonlarıly meşgul olmaları klinik ortamı etkin olarak kullanamamalarına neden olmakta ve klinik öğretimi olumsuz etkilemektedir.

$\mathrm{Bu}$ çalışma öğrencilerin yaşlarının artmasıyla günlük internete bağlanma süresinin azaldığını göstermektedir (Tablo 4). Şahin (2011) aynı şekilde yaş ile internet bağımlılı̆̆ negatif ilişki olduğunu belirtmiştir (36). İnternet kullanım süresi ve bağımlılığın yaş küçüldükçe artması, çocukların internet ile daha erken tanışması ve internet kullanmaya başlama yaşının giderek daha küçük yaşlara kayması ile açılanmaktadır (36-37). Öğrencilerin yaşları arttıkça klinik uygulamalarda akıllı telefon kullanım sürelerinin de arttığı görüldü (Tablo 4). Klinik uygulamalarda dördüncü sınıf öğrencilerinin tıbbi kelimelerin anlamına bakma, mesleki bilgilerini güncelleme, ilaç bilgisi araştırma amaciyla daha fazla akıllı telefon kullandikları görülmüştür (Tablo 4). Dördüncü sınıf öğrencilerinin diğer öğrencilere göre akıllı telefonlarını daha fazla mesleki ve eğitim amaçlı kullandıkları söylenebilir. Meslek kavramı ve mesleğe uyum sürecinin başladığı birinci sınıfta öğrencilerin ise akıllı telefonlarını meslek ve eğitim amaçlı kullanmak yerine, üniversiteye başlamanın verdiği bağımsızlık duygusu/yalnızlık duygusu ile beraber daha çok iletişim kurma amacıyla kullandıkları söylenebilir.

\section{Sonuç ve Öneriler}

Hemşirelik öğrencilerinin akıllı telefon kullanım 
özelliklerini belirlemek amacıyla tanımlayıcı tipte yapılan bu çalışmanın sonucunda; öğrencilerin teorik derslerde ve klinik uygulamalarda akıllı telefonlarını yaygın olarak ve daha çok iletişim amacıyla kullandıkları belirlendi. Çalışmada ögrencilerin teorik derslerde akıllı telefonu daha çok ders dışı amaçlarla, kliniklerde ise uygulamaya yönelik kullandıkları bulundu. Öğrencilerin yaşlarının günlük internet kullanımını ve klinik uygulamalarda akıllı telefon kullanım sürelerini etkilediği, sınıflarının ise teorik derslerde ve klinik uygulamalarda ak1llı telefon kullanım amaçlarını etkilediği bulundu.

$\mathrm{Bu}$ sonuçlar doğrultusunda;

- Üniversiteler tarafından öğrencilere yönelik akıllı telefon kullanımının yararları, zararları ve akılcı kullanımı ile ilgili eğitim programlarının düzenlenmesi,

- Üniversiteler ve sağlik kurumları tarafından akıllı telefonlar ve medya kullanımına yönelik politikalar, kurallar hakkında öğrencilerin bilgilendirilmesi ve denetlenmesi,

- Hemşirelik öğrencilerinin akıllı telefon kullanım özelliklerini belirlemek amaciyla daha geniş ölçekli çalışmaların farklı üniversitelerde yapılmas1 önerilmektedir.

\section{Kaynaklar}

1. Hinton S, Hjorth L. Understanding Social Media. London, England and Thousand Oaks 2013, CA: Sage.

2. Kim S, Zeelim-Hovav A. The impact of smart phone usability on group task performance in a university environment: Media Synchronicity Perspective. International Conference on Information Resources Management 2011, http://aisel.aisnet.org/confirm2011.

3. Deloitte. The state of the global mobile consumer; Connectivity is core. London, May-June 2012, 1-23. Retrived May 2, 2015, from http://www.lriti.org/dttl_TMT_MobileConsumer_Final_171212.pdf.

4. Binark M. Yeni medya çalışmalarında yeni sorular ve yöntem sorunu. Yeni Medya Çalışmaları. (Der.) Mutlu Binark, Ankara, 200721-44.

5. Türkiye İstatistik Kurumu, Ulaştırma, Denizcilik ve Haberleşme Bakanlığı, Bilgi Teknolojileri ve İletişim Kurumu 2015.
Erişim:

8.05.2015.

http://www.tuik.gov.tr/Start.do.

6. Nursing and Midwifery Board of Ireland.

Guidance to nurses and midwives on social media and social networking 2013, June. Retrived May 14, 2015, from https://www.nmbi.ie/Standards-

Guidance/More-Standards-Guidance/SocialMedia-Social-Networking.

7. Aldhaban F. Exploring the adoption of smartphone technology: Literature Review, 2012 Proceedings of PICMET ' 12. Technology Management for Emerging Technologies, July 29, 2012-August 2, 2012, Vancouver, Canada, 2758-2770.

8. International Data Corporation. Worldwide Smartphone 2012-2016 Forecast Update. 2012, Retrieved January 15, 2015, from http://www.idc.com/getdoc.jsp?containerId= 235193\#.UP-6bR26fSk.

9. Von Muhlen M, Ohno-Machado L. Reviewing social media use by clinicians. Journal of The American Medical Informatics Association 2012;19(1):777-781. doi:10.1136/amiajnl2012-000990.

10. Kung YM, Oh S. Characteristics of nurses who use social media. Computers Informatics Nursing 2014;32(2):64-72.

11. Journal of Pioneering Medical Sciences Blogs. Effects of Social Media on Nursing. 2013, July 30. Retrived May 5, 2015, from http://blogs.jpmsonline.com/2013/07/30/effec ts-of-social-media-on-nursing/.

12. Pitt M, Bennett J. Workforce ownership of space in a space sharing environment. Journal of Facilities Management 2008;6(4):290-302..

13. Cho S, Lee E. Distraction by smartphone use during clinical practice and opinions about smartphone restriction policies: A crosssectional descriptive study of nursing students. Nurse Educ Today 2016;40:128133.

14. Ahn SY, Kim YJ. The Influence of Smart phone use and stress on quality of sleep among nursing students. Indian Journal of Science and Technology 2015;8(35):1-6.

15. David P, Kim JH, Brickman JS, Ran W, Curtis CM. Mobile phone distraction while studying. New Media \& Society 2015;17(10):1661-1679. 
16. Ardıç Çobaner A, Işık T. Hemşireler arasında sosyal medya kullanımının yarar ve risklerinin tıp etiği bağlamında tartışılması [Discussing the benefits and risks of social media use among nurses in the context of medical ethics]. Türkiye Biyoetik Dergisi [Turkish Journal of Bioethics] 2014;1(1):137-148.

17. Kheokao J, Siriwanij W, Yingrengreung S, Krirkgulthorn T. Media use of nursing students in Thailand. 4th International Symposium on Emerging Trends and Technologies in Libraries and Information Services 2015;1:123-127.

18. Fidancioğlu H, Beydağ KD, Gök Özer F, Kızılkaya M. Sağlı yüksekokulu öğrencilerinin internet kullanımına yönelik görüşleri [Unıversıty School For Health Sciences Students' Opinions About Internet Usıng]. Maltepe Üniversitesi Hemşirelik Bilim ve Sanat Dergisi 2009;2(1):3-9.

19. Munene AG, Nyaribo YM. Effect of social media pertication in the workplace on employee productivity. International Journal of Advances in Management and Economics 2013;2(2):141-150.

20. Özdemir S. Sosyal medyanın örgüt içi iletişimdeki rolü. Yüksek Lisans Tezi, Süleyman Demirel Üniversitesi, Sosyal Bilimler Enstitüsü 2014, Isparta, Türkiye.

21 Çakır F, Demir N. Üniversite öğrencilerinin akıllı telefon satın alma tercihlerini belirlemeye yönelik bir araştırma [A Study on Determining Preferences of University Students' Purchasing Smartphone]. Dokuz Eylül Üniversitesi İktisadi ve İdari Bilimler Fakültesi Dergisi 2014;29(1):213-243.

22. Ersun A, Şahin Köze B, Muslu G, Beytut D, Başbakkal Z, Conk Z. Hemşirelik yüksekokulu öğrencilerinde internet kullanımı ile sosyal destek sistemi arasındaki ilişkinin incelenmesi [Investigation of The Relation Between The Use of Internet Among Nursing Students and Social Support Systems]. İstanbul Üniversitesi Florence Nightingale Hemşirelik Yüksekokulu Dergisi 2012;20(2):86-92.

23. Korkmaz M, Kılıç B, Demiray E, Gürkan A, Hablemitoğlu Ş, Yücel AS, Kırık AM. Hemşirelerin sosyal medya kullanımı ve yaptıkları işe karşı algı düzeyinin uygulamalı bir örneği [An applied study: Nurses' use of social media and the level of their perceptions concerning their jobs]. Uluslararas1 Hakemli Beşeri ve Akademik Bilimler Dergisi [International Peer-Reviewed Journal of Humanities and Academic Sinence] 2014;4(13):59-84.

24. Sandholzer M, Deutsch T, Frese T, Winter A. Predictors of students' self-reported adoption of a smartphone application for medical education in general practice. BMC Medical Education 2015;15(1):91.

25. Çoşansu G. Verilerin analizi ve yorumlanması. İçinde Hemşirelikte araştırma, süreç, uygulama ve kritik (2.Bask1, sy.235279) 2015, İstanbul: Nobel Tip Kitabevleri.

26. Gümüş İ, Örgev C. Önlisans öğrencilerinin akıllı cep telefon kullanmalarının başarı ve harcama düzeylerine olası etkileri üzerine bir çalışma. ISCAT/Akademik Platform, 2015, April 10:310-315. http://www.iscat.info/Content/Pages/Accept edPapers.aspx. Erişim tarihi: 15.12.2016.

27. Uğur NC, Turan AH. Üniversite öğrencilerinin mobil uygulamaları kabulü ve kullanımı: Sakarya Üniversitesi örneği [College students' acceptance and usage of mobile applications: Sakarya University case]. İnternet Uygulamaları ve Yönetimi 2015;6(2):63-79.

28. Willemse I, Waller G, Süss D, Genner S, Huber AL. JAMES: Jugend, Aktivitäten, Medien-Erhebung Schweiz [JAMES: Youth, Activity, Media-Data Switzerland], Zürich: Zürcher Hochschule für angewandte Wissenschaften, Ergebnisbericht zur JAMESStudie 2012, 1-59.

29. Cho M. The Relationships among Smart phone use motivations, addiction, and selfcontrol in nursing students. Journal of Digital Convergence 2017;12(5):311-323.

30. Tüysüz C, Balaman F, Atalar T. Eğitim fakültesi öğrencilerin internet kullanım amaçlarının belirlenmesi [Determining education faculty students' internet usage purpose]. Batman Üniversitesi Yaşam Bilimleri Dergisi [Batman University Journal of Life Sciences] 2012;1(1):251-260.

31. Mok JY, Choi SW, Kim DJ, Choi JS, Lee J, Ahn H, Choi EJ, Song WY. Latent class analysis on internet and smartphone addiction 
in college students. Neuropsychiatric Disease And Treatment 2013;10(1):817-828.

32. Kim TH, Kang MS. Type analysis and countermeasures of side effects of using smart phone. Journal of The Korea Institute of Information and Communication Engineering 2013;17(12):2984-2994.

33. Korea Internet and Security Agency. Research on The Mobile Internet Use. Seoul. Korea Internet and Security Agency 2013. Retrived April 20, 2015, from http://www.kisa.or.kr/eng/usefulreport/survey Report_View.jsp?cPage $=2 \& p \_N o=262 \& b \_N$ $\mathrm{o}=262 \& d \_\mathrm{No}=57 \& \mathrm{ST}=\& \mathrm{SV}=$.

34. Kwon M, Kin DJ, Cho H, Yang S. The smartphone addiction scale: development and validation of a short version for adolescents. PLoS One 2013;8(12):e83558.
35. Aslan A, Tutgun Ünal Ü. Eğitim fakültesi öğrencilerinin cep telefonu kullanım alışkanlıkları ve amaçlarının incelenmesi. International Journal of Human Sciences 2013;10(1):182-200.

36. Alam SS, Hashim N, Ahmad M, Wel C, Nor $\mathrm{S}$, Omar N. Negative and positive impact of internet addiction on young adults: Empericial Study in Malaysia. Journal of Intangible Capital 2014;10 (3): 619-638. http://dx.doi.org/10.3926/ic.452.

37. Şahin C. An analysis of internet addiction levels of individuals according to various variables. The Turkish Online Journal of Educational Technology 2011, October 4;10 (4):60-66. Erişim: 12.042015. http://www.tojet.net 